\title{
Oswald de Andrade, filósofo da diferença ${ }^{1}$
}

\author{
Jorge Vasconcellos ${ }^{1}$
}

\section{RESUMO:}

Oswald de Andrade como filósofo, um filósofo brasileiro. Oswald de Andrade pensador do real. Oswald de Andrade um filósofo da diferença. Estas são as premissas norteadoras deste artigo. Isso porque entendemos que O.A. constitui, para além de seu ativismo políticoliterário e da força fabulatória de sua obra, poderoso pensamento sobre "o que é o Brasil?" e sobre "quem são os brasileiros?"; valendo-se para tal de categorias que, insistimos, são estritamente filosóficas. Procuraremos mostrar como Oswald de Andrade se filiaria ao que denominamos de filosofia da diferença, linhagem filosófica que articula Nietzsche a Deleuze \& Guattari.

Palavras-chave: Antropofagia ; filosofia da diferença; ontologia; estética; Oswald de Andrade; Deleuze \& Guattari; Nietzsche.

\begin{abstract}
:
Oswald de Andrade as a Brazilian philosopher, a thinker of the real. These are the guiding premises of this article. We understand that, in addition to his political/aesthetical activism, in addition to the literary strength of his fictional work, O.A. produces a powerful thought about "what Brazil is" and "who Brazilians are" by making use of strictly philosophical categories. We try to show that this thought belongs to a philosophical lineage that articulates Nietzsche, Deleuze \& Guattari.
\end{abstract}

Key words: anthropophagy; philosophy of difference, ontology, aesthetics; Oswald de Andrade; Deleuze \& Guattari; Nietzsche.

\footnotetext{
${ }^{1}$ Doutor em Filosofia/UFRJ. Professor do Dept ${ }^{\circ}$ de Artes e Estudos Culturais e do Programa de Pósgraduação em Estudos Contemporâneos em Artes/PPGCA na Universidade Federal Fluminense. Autor de Deleuze e o Cinema. Rio: Editora Ciência Moderna, 2006. Publicou recentemente, em coautoria com Guilherme Castelo Branco, Arte, Vida e Política: ensaios sobre Foucault e Deleuze. Rio: Edições LCVUERJ, 2010.
} 
Oswald de Andrade propõe a, talvez, mais poderosa interpretação já feita do Brasil. Nele encontramos ideias como: 'Só gosto do que não é meu'; 'aprecio apenas o que é do outro'; 'preciso comer o que é de outrem para aí tornar-me o que sou'. Estas são algumas das palavras-de-ordem, ou melhor dizendo palavras-valise, livremente por nós interpretadas do pensamento da Antropofagia de Oswald de Andrade. Essas palavras-Ideias são as orientadoras do que entendemos ser o sentido do Manifesto Antropófago. Partiremos deste texto oswaldiano para dar a pensar as relações entre Antropofagia e Filosofia, mostrando como esta conexão estaria ainda por ser realizada de modo rigoroso. Enfatizaremos, sobretudo, a importância do texto de O.A. para interpretarmos a cultura brasileira, em seus mais radicais aspectos, seja esta uma radicalidade histórica, sociológica e/ou antropológica; mas, principalmente, em sua radicalidade filosófica. Isso por que afirmamos que Oswald pode e deve ser pensado, antes de tudo, como um pensador, como um filósofo: um filósofo brasileiro.

Evidentemente, quando estamos apontando um filósofo brasileiro, é preciso que se diga que não estamos defendendo a posição de que existam estritamente falando filosofias nacionais. Não existe propriamente uma filosofia alemã, uma filosofia francesa, ou mesmo uma filosofia grega em seu caráter nacional. Pois, entendemos que a filosofia aspira e implica um sentido de universalidade que orienta meditações acerca da dimensão do humano, da terra e do mundo. Não obstante, Hegel é um filósofo alemão, Pascal um filósofo francês, assim como Platão é um filósofo grego. Nesse sentido, a despeito de recusarmos a alcunha de uma filosofia brasileira, reafirmamos que Oswald de Andrade é um filósofo brasileiro.

O que então faz da Antropofagia oswaldiana uma filosofia, no sentido forte do termo, isto é, um pensamento filosófico constituído, que investiga e rivaliza com o cânone da filosofia ocidental, que compõe visão própria do mundo, instituindo uma cosmovisão do que existe, do que é... Apresentando-se, ao fim e ao cabo, como uma teoria do real.

Em suma, perguntamos pelo que faz a Antropofagia constituir-se enquanto uma ontologia? Já que ela, a Antropofagia, é um saber complexo e sistemático, com categorias singulares e operativas, tornada pelo movimento do pensamento uma ciência do ser enquanto ser. Seria 
ela, a Antropofagia, uma ontologia para pensar o Brasil e os brasileiros? Que fique claro que ao designarmos o pensamento da Antropofagia de Oswald de Andrade como uma ontologia, antes de tudo, trata-se de uma ontologia não-metafísica. Ou seja, escapa-se da perspectiva ontológica pautada pela representação que se caracterizaria pela subordinação da diferença à identidade, a subsunção das singularidades às potências do Uno. Recusa-se pensar o ser refém às relações do Análogo, às similitudes do Semelhante e à identidade do Mesmo. Em suma, as derivações do platonismo.

A indagação “o que é o Brasil e quem são os brasileiros?” não é o mesmo que a busca pela essência da brasilidade e pela identidade brasileira, como veremos. Trata-se mais de uma orientação de sentido, um colocar-se no horizonte problemático do pensamento. Daí, antes de tudo, a Antropofagia é uma filosofia, Oswald Andrade, um filósofo.

Se assim é, então, quais os problemas a serem enfrentados pela antropofagia oswaldiana? Em que plano de imanência possível emerge esses problemas? Quais seus operadores, seus conceitos? Quais seus personagens conceituais? Enfim, a qual tradição filosófica ela se filia e com qual rivaliza? Já que fazer filosofia, melhor dizendo, o exercício da prática filosófica implica, a nosso ver, necessariamente: enfrentar e recolocar problemas filosóficos; traçar e instituir um plano de imanência a uma determinada filosofia; criar e operar conceitos que habitam este plano; forjar e designar personagens conceituais que se articulam aos conceitos. Fazer crítica e clínica filosófica.

Um pequeno deslocamento aqui se faz necessário, pois, partimos das idéias de Gilles Deleuze e Félix Guattari, e da concepção que ambos engendram do que seja a filosofia e o filosofar, para pensar as relações entre Antropofagia e Filosofia. Assim, carece explicitar o que seja plano de imanência, conceitos e personagens conceituais para os pensadores franceses.

Em $O$ que é a filosofia? ${ }^{2}$, os autores desenvolvem a noção de 'personagem conceitual'. Nesse livro os personagens conceituais constituem-se como elementos pré-filosóficos ao próprio filosofar, tais quais os conceitos, que seriam propriamente filosóficos, enquanto o plano de imanência se estabeleceria como elemento pré-filosófico, uma espécie de ‘topos’ 
dos conceitos. A ideia de plano de imanência está diretamente implicada à ideia de conceito em Deleuze e Guattari, à sobrevida dos conceitos filosóficos.

O que são conceitos sob esse ponto de vista filosófico? Os conceitos são totalidades fragmentárias que não se ajustam umas às outras, já que suas bordas não coincidem. Eles nascem de um lance de dados, não compõem um quebra-cabeças. De todo modo, eles ressoam à filosofia que os cria, pois só é filosofia o pensamento que se dá a inventar conceitos. Contudo, os conceitos não constituem por si só um plano de imanência. O plano de imanência não é um conceito particular ou um conceito geral, nem por sua vez, um Grande Conceito a englobar todos os outros conceitos, ele é a pré-condição de existência de todo conceito filosófico, ele é o solo onde os conceitos devem vir à luz. O plano de imanência é a terra do conceito.

Novamente, então, o que é um conceito para o sentido da filosofia que apontam os escritos de Gilles Deleuze e Félix Guattari? Os conceitos são construções na perspectiva deleuziana, a própria filosofia é uma espécie de construtivismo, daí a importância de traçar planos (de imanência), erguer platôs (em espaços-quaisquer), semear campos (de força). A imanência é a argamassa destes campos, platôs e planos; e os conceitos são a sua ferramenta. Tanto que em linhas gerais, para essa concepção, os conceitos teriam quatro grandes características: 1) Eles não são simples, melhor dizendo, não há conceito simples. Todo e qualquer conceito possui componentes, e se definem por eles. Eles, os conceitos, possuem uma espécie de cifra. São multiplicidades. Todo conceito é implicado por multiplicidades; 2) Todo conceito possui um devir que lhe concerne. Os conceitos se acomodam uns aos outros, compondo seus respectivos problemas; 3) Todo conceito é simultaneamente absoluto e relativo: relativo a seus próprios componentes, aos demais conceitos, a partir do plano ao qual se limita, aos problemas que enfrenta, porém, absoluto pela condensação que opera, pelo lugar que ocupa no plano, pelas condições que impõe ao problema; 4) Um conceito nunca é discursivo, pois a filosofia não é uma formação discursiva, já que não encadeia proposições. Os conceitos são, como dissemos, ferramentas.

Essa é a articulação que conjuga conceitos e filosofia, ou mais precisamente, entre plano de imanência e os conceitos que o compõem, que garantem ao "filosofante", aquele que estuda a filosofia e interpreta a sua história, conhecer e restituir um determinado filósofo ou 
mesmo um sistema de pensamento. O plano de imanência torna possível desenhar diagramas na cartografia do pensamento filosófico. O plano de imanência faz aparecer um rosto em meio à bruma da paisagem filosófica.

Por sua vez, a idéia de personagem conceitual talvez seja a mais radical e extraordinária desta concepção do filosofar proposta por Deleuze e Guattari. Por exemplo, em $O$ que é a filosofia? Deleuze e Guattari apresentam Sócrates como personagem conceitual de Platão. Este "Sócrates", os autores deixam claro, não se trata do Sócrates histórico, nem propriamente um simples personagem por intermédio do qual as ideias platônicas seriam defendidas, seu porta-voz ou alter-ego, mas de um intercessor. Os personagens conceituais são os verdadeiros sujeitos da filosofia. Logo, descartamos qualquer alusão a que os personagens conceituais sejam meramente ilustrativos, eles são pró-ativos na construção de uma teoria filosófica. No entanto, eles não são conceitos, pois eles dramatizam estas filosofias, não são ferramentas como os conceitos, eles fazem a filosofia entrar em jogo, eles fazem-nas jogar, como em um jogo de cena.

Acreditamos que o texto oswaldiano pode ser lido sob essa perspectiva deleuziana da filosofia. Isso à revelia de fortes correntes interpretativas do Manifesto Antropófago, que constitui a fortuna crítica ao legado de O.A., e têm como uma de suas linhas mestras a hipótese de destacar que seu sentido é aquele o de 'ler' o Brasil por intermédio de metáforas, contidas na própria letra do texto de Oswald.

Por exemplo, segundo Benedito Nunes, em seu ensaio de introdução ao sexto volume das Obras Completas de Oswald de Andrade - justamente aquele que reúne os dois manifestos determinantes ao Modernismo de 22 (NUNES: 1972) propõe a "devoração” como símbolo do processo antropofágico simultaneamente como: 'metáfora', 'diagnóstica' e 'terapêutica'. O consagrado crítico propõe como eixo interpretativo que a metáfora seria orgânica, já que se inspira em cerimônia guerreira de imolação dos inimigos pelos Tupis, que devoram seus algozes após o combate. Por sua vez, a devoração antropofágica seria ainda um diagnóstico da sociedade brasileira, traumatizada pela repressão colonizadora que teria nos condicionado. E, por fim, a devoração faria às vezes de uma terapêutica, praticada na ação violenta e sistemática aos mecanismos sociais e políticos, aos hábitos intelectuais e às manifestações literárias e artísticas que teriam produzido este trauma repressivo. 
Somos contrários a essa interpretação. Recusamos este sentido dado à Antropofagia, especialmente à idéia de "devoração", como metáfora. Defendemos que: onde se lêem metáforas, lemos conceitos.

Conforme enunciamos: Oswald de Andrade, como um filósofo, é um inventor de conceitos - "devoração" opera como um conceito filosófico. E como nenhum conceito é simples, estes possuem sempre elementos. Diríamos, desse modo, que a idéia de "assimilação" presente no processo de deglutição do outro, seria um dos elementos do conceito de devoração antropofágica. Ao apontarmos esta idéia de "devoração antropofágica" como conceito filosófico nos leva a fazer a pergunta por qual ordem de problemas este conceito deve enfrentar se faz então necessária. Dito de outro modo, quais os problemas filosóficos, propriamente ditos, que são colocados pela Antropofagia? Diríamos, a grande questão da Identidade, mais especificamente das relações entre identidade e diferença no bojo do processo da constituição de um Povo. No caso o Povo Brasileiro. O 'ser' brasileiro como o avesso de uma forma identitária nos parece ser o topos das idéias filosóficas de Oswald de Andrade.

Por sua vez, qual o plano de imanência que sustenta esses conceitos e faz emergir seus personagens conceituais? Diríamos, estamos diante de um pensamento da pura imanência, como na linhagem filosófica de um Spinoza, de um Nietzsche, de um Deleuze. Pensar o ser é pensá-lo como afirmação do devir... é como pensar os processos subjetivos como transformação do eu em um outro, um outrar-se como na expressão criada por Fernando Pessoa.

Por fim, qual, ou quais, personagens conceituais são instaurados pela prática filosófica da devoração antropofágica? Arriscamos dizer: o Bispo Sardinha ${ }^{3}$ é um personagem conceitual de Oswald de Andrade.

Oswald, ao apresentar sua Antropofagia, estava produzindo uma rigorosa e meticulosa análise filosófica do Brasil, um diagnóstico do nosso presente, um sentido aos nossos futuros. Seu texto, mesmo que ao comportar expressões e palavras que sugerem as mais extravagantes imagens, que remetem muitas vezes às vanguardas literárias européias, como, por exemplo, ao surrealismo, ensejava em seu bojo uma construção que é, de fato, 
conceitual. Assim, uma expressão como "a alegria é prova dos noves" não seria apenas um gracejo que reivindicaria ao povo brasileiro a festa, o carnaval, o rito jubiloso encarnado, o êxtase; mas a afirmação da alegria como sentido (do existente) e valor (da vida). Ou ainda outra enunciação célebre contida no Manifesto: “O espírito recusa-se a conceber o espírito sem o corpo. O antropomorfismo. Necessidade da vacina antropofágica." Trata-se de descartesianizar a filosofia. Tratava-se de descartar Descartes. Ou seja, recusar o paralelismo cartesiano e propor a este um antídoto: 'a vacina antropofágica'. Ela mesma, um conceito. Estamos diante de um médico da civilização, de um psicólogo da cultura, como Nietzsche, produzindo a sintomatologia da modernidade enferma. Oswald parece evocar o sentido da idéia de "grande saúde" em Nietzsche com seu pensamento antropofágico.

Nietzsche não se faz notar apenas pelas citações explícitas ou subjacentes no próprio Manifesto, mas, também pelo projeto filosófico presente no pensamento da antropofagia de Oswald. Como aponta Maria Cristina Franco Ferraz, em artigo que articula a Genealogia da Moral de Nietzsche ao Manifesto (2008), Oswald de Andrade digere o dilema do ser e do não-ser tão caros à metafísica clássica e à tradição ocidental, devolvendo-o em forma de paródia e alegria: ao invés do "To be or not To be", em seu lugar o "Tupi or not Tupi”. Eis a questão da devoração antropofágica. Segundo Ferraz, Oswald teria, nesse sentido, se aproximado da perspectiva nietzschiana e do estatuto da afirmação em Nietzsche.

A Antropofagia é uma filosofia do Sim, um dizer afirmativo: é isto mesmo, a vida. A vida nos trópicos, sob o sol... América do Sal, América do Sul, América do Sol... Ser antropófago é mais que voltar às raízes do homem primitivo a devorar e assimilar a cultura de outrem, pois,nos parece que os caminhos apontados pela Antropofagia sejam exatamente aqueles de inaugurar o novo, fazendo com que tudo o que é de-fora seja incorporado, modificado, regurgitado não evidentemente por nosso entendimento, mas por nossos intestinos. Ainda como Nietzsche, um pensar que vem das vísceras, um pensamento visceral. A Antropofagia (Oswald de Andrade) produziu, juntamente com a Tropicália (Hélio Oiticica), o Tropicalismo (Caetano \& Gil), O Cinema Novo (Glauber Rocha), O Teatro Oficina (José Celso Martinez Corrêa), uma interpretação conceitual e sensível do Brasil. 
Ele mesmo, Oswald de Andrade, nos diz o significado da ANTROPOFAGIA:

\begin{abstract}
A ANTROPOFAGIA ritual é assinalada por Homero entre os gregos e segundo a documentação do escritor argentino Blanco Villalta, foi encontrada na América entre os povos que haviam atingido uma elevada cultura - Asteca, Maias, Incas. Na expressão de Colombo, comiam los hombres. Não o faziam, porém, por gula ou por fome. Tratava-se de um rito que, encontrado também nas outras partes do globo, dá a idéia de exprimir um modo de pensar, uma visão de mundo, que caracterizou certa fase de toda a humanidade.
\end{abstract}

Considerada assim, mal se presta à interpretação materialista e imoral que dela fizeram os jesuítas e colonizadores. Antes pertence como ato religioso ao rico mundo espiritual do homem primitivo. Contrapõe-se em seu sentido harmônico e comunial, ao canibalismo que vem a ser a antropofagia por gula e também a antropofagia por fome, conhecida através da crônica das cidades sitiadas e dos viajantes perdidos.

A operação metafísica que se liga ao rito antropofágico é a da transformação do tabu em totem. Do valor oposto, ao valor favorável. A vida é devoração pura. Nesse devorar que ameaça a cada minuto a existência humana, cabe ao homem totemizar o tabu. Que é o tabu senão o intocável, o limite? Enquanto na sua escala axiológica fundamental, o homem do Ocidente elevou as categorias do seu conhecimento até Deus, supremo bem, o primitivo instituiu a sua escala de valores até Deus, supremo mal. Há nisso uma radical oposição de conceitos que dá uma radical oposição de conduta. (2011, 138-139) 
Como tal caracterizamos aqui não só a figura de Oswald de Andrade, como constituinte à imagem de filósofo, como de autor inaugural da maior radicalidade filosófica criada entre nós. E mais, Oswald está filiado à linhagem dos pensadores da diferença, do heterogêneo, da pluralidade e postulante à construção de uma ontologia não-metafísica do que seria a brasilidade. Oswald de Andrade/Nietzsche/Deleuze.

Oswald de Andrade, filósofo da diferença. 


\section{REFERÊNCIAS:}

ANDRADE, Oswald. ANDRADE, Oswald. "A crise da filosofia messiânica". IN: Oswald de Andrade: A Utopia Antropofágica. São Paulo: Editora Globo, 2011, pp. 138-9.

DELEUZE, Gilles e GUATTARI, Félix. O que é a filosofia?. Tradução de Bento Prado Jr e Alberto Alonso Muñoz. São Paulo: Editora 34, 1992.

FERRAZ, Maria Cristina Franco. "Nietzsche Educador: Negatividade, Afirmatividade e Antropofagia". IN: Nietzsche, Filosofia e Educação. Vânia Dutra de Azevedo (org.). Ijuí: Editora Unijuí, 2008.

NUNES, Benedito. "Antropofagia ao Alcance de Todos". IN: Obras Completas - 6. Oswald de Andrade: Do Pau-Brasil à antropofagia e às utopias. Rio de Janeiro: Editora Civilização Brasileira, 1972.

\footnotetext{
${ }^{1}$ Texto ligeiramente modificado de intervenção em Mesa de Conversação Filosófica ao DIA MUNDIAL DA FILOSOFIA, promovido pela UNESCO-ONU, em 11 de novembro de 2009, na Casa da Ciência, Rio/RJ. Brasil.

${ }^{2}$ DELEUZE, Gilles e GUATTARI, Félix. $O$ que é a filosofia?. Tradução de Bento Prado Jr e Alberto Alonso Muñoz. São Paulo: Editora 34, 1992.

${ }^{3}$ Isso mesmo, falamos daquele pároco, $1{ }^{\circ}$ Bispo do Brasil, que teria sido devorado pelos Caetés.
} 